\title{
ОПТИМИЗАЦИЯ МЕР ВЕДЕНИЯ БЕРЕМЕННОСТИ И РОДОВ У ЖЕНЩИН С ДИСПЛАЗИЕЙ СОЕДИНИТЕЛЬНОЙ ТКАНИ
}

\section{OPTIMIZATION OF MEASURES \\ FOR MANAGING PREGNANCY \\ AND CHILDBIRTH IN WOMEN WITH CONNECTIVE TISSUE DYSPLASIA}

\section{T. Fadeeva \\ V. Bitsadse}

Summary. The conceptual basis for the development of preventive measures should be the responsibility for creating conditions that cause reproductive health disorders; prevention and early detection of various health disorders of the population that occur when industrial and environmental factors affect the reproductive function.

To implement a system of hygienic training and education of a healthy lifestyle, family values among all segments of the population.

To improve technologies that ensure the hygienic and sanitary safety of patients and medical personnel in medical and preventive institutions.

Many women, while still in adolescence, learn about the presence of nondifferential connective tissue dysplasia, which is recorded in their medical records. If pregnant women have a diagnosis of NDT before pregnancy, first of all, it is necessary to conduct a specialized reception, which is carried out up to 12 weeks. During this reception, studies are carried out on the absence of visceral manifestations of NDST, oxyproline and magnesium in the blood serum.

Keywords: dysplasia, pregnancy, reproductive health, childbirth, connective tissues.
Фадеева Татьяна Сергеевна

Д.м.н., профессор РАН, ФГАОУ ВО «Первый МосковскИй государственный медицинский университет им. И.М. Сеченова» Минздрава России (Сеченовский Университет)

Fdv_tana@mail.ru

Бицадче Виктория Омаровна

ФГАОУ ВО «Первый Московский государственный медицинский университет им. И.М. Сеченова» Минздрава России (Сеченовский Университет)

Vikabits@mail.ru

Аннотация. Концептуальной основой развития профилактических мероприятий должна стать ответственность за создание условий, вызывающих нарушения репродуктивного здоровья; профилактика и раннее выявление различных нарушений состояния здоровья населения, возникающие при воздействии производственных и факторов окружающей среды на репродуктивную функцию.

Осуществлять среди всех слоев населения систему гигиенического обучения и воспитания здорового образа жизни, ценности семьи.

Совершенствовать технологии, обеспечивающие гигиеническую и санитарную безопасность пациентов и медицинского персонала в лечебно-профилактических учреждениях.

Многие женщины, находясь еще в юношеском возрасте, узнают о наличии недифференциальной дисплазии соединительной ткани, что фиксируется В их медицинских картах. При наличии у беременных женщин диагноза НДСТ до беременности в первую очередь необходимо проведение специализированного приема, который проводится до 12 недель. В ходе данного приема производятся исследования отсутствия висцеральных проявлений НДСТ, оксипролина и магния в сыворотки крови.

Ключевые слова: дисплазия, беременность, репродуктивное здоровье, роды, соединительные ткани.

по охране репродуктивного здоровья молодежи и беременных женщин [2-3].

Кроме того, Конституцией РФ ст. 38 закреплено то, что материнство и детство, и институт семьи находится всецело под защитой государства. Ст. 41 Конституции РФ предусматривает финансирование федеральных программ охраны и укрепления здоровья населения, принимаются меры по развитию государственной, муниципальной, частной систем здравоохранения, поощряется деятельность, способствующая укреплению здоровья 
человека, развитию физической культуры и спорта, экологическому и санитарно-эпидемиологическому благополучию [4].

В развитие федеральных законодательных актов и программ приняты и реализуются соответствующие документы в субъектах Российской Федерации.

Обеспечение конституционных прав граждан Российской Федерации на получение гарантированной бесплатной медицинской помощи осуществляется в рамках принятой Правительством Российской Федерации Программы государственных гарантий обеспечения граждан Российской Федерации бесплатной медицинской помощью.

Аборты по желанию (статья 36 Основ Законодательства об охране здоровья граждан Российской Федерации) производятся за счет средств обязательного медицинского страхования (ОМС).

В целях реализации настоящей Концепции необходимо обеспечение приоритетного гарантированного финансирования мероприятий по охране репродуктивного здоровья населения за счет бюджетов и источников всех уровней.

Для выполнения Концепции следует продолжить разработку и утверждение соответствующих нормативно-правовых актов и федеральных целевых программ [5].

Осуществлять среди всех слоев населения систему гигиенического обучения и воспитания здорового образа жизни, ценности семьи.

Совершенствовать технологии, обеспечивающие гигиеническую и санитарную безопасность пациентов и медицинского персонала в лечебно-профилактических учреждениях.

\section{Течение беременности и родов у женшин с неАифференцированной Аисп^азией соеАинительной ткани}

В первом триместре беременности в группе женщин с НДСТ в большей степени проявляются следующие осложнения: ранний токсикоз и угроза прерывания беременности, что, однако, не может быть статистически достоверным.

Статистически достоверными $(\mathrm{p}<0,05)$ оказались осложнения в группе женщин с НДСТ, связанные с наличием воспалительных заболеваний половых путей, например, кольпитов и вагинитов неспецифической этиологии, и анемии. Необходимо отметить, что уровень эритроци- тов и уровень гемоглобина у беременных без НДСТ был заметно ниже аналогичных показателей в контрольной группе ( $p=0,014$ и $p=0,0009)$. В большей степени уженщин с недифференциальной дисплазией соединительной ткани в первом триместре беременности наблюдались следующие осложнения: угроза прерывания беременности и воспалительные заболевания половых путей.

Кроме того, нельзя исключать тот факт, что наличие и выраженность угрозы прерывания статистически находились в обратной корреляционной зависимости с уровнем тромбоцитов $(R=-0,42 ; p=0,0095)$.

Во втором триместре беременности в группе женщин с НДСТ, как и среди женщин контрольной группы, в большей степени проявлялась анемия, которая имеет очень высокую степень распространенности у женщин с недифференциальной дисплазией соединительной ткани.

Необходимо учитывать и тот факт, что в большинстве случаев у женщин с недифференциальной дисплазией соединительной ткани в первом и втором триместре плод еще со стадии эмбриона развивается в условиях недостатка кислорода, который зависит от наличия гемического фактора. В подтверждение этому у беременных женщин с НДСТ во втором триместре присутствует низкие показатели уровня эритроцитов с высокой степенью достоверности $(R=-0,5266, p=0,0003)$ коррелируют с развитием фетоплацентарной недостаточности в третьем триместре беременности, которая затем верифицируется гистологически.

У женщин с НДСТ в большей степени проявляется такое осложнение как низкая плацентация. Еще одним фактом, на который указывает в своей работе Маслеников A.B, является наличие у женщин с НДСТ в большей степени угрозы прерывания беременности во втором триместре, особенно ярко это проявляется если у женщины присутствуют низкие показатели тромбоцитов в 1 триместре беременности ( $R=-0,4149, p=0,0095)$, и именно с низким содержанием тромбоцитов коррелирует такое осложнение, как низкая плацентация $(R=-0,3876$, $\mathrm{p}=0,0162$ [ [6]. Других достоверных корреляций низкого уровня тромбоцитов в первом триместре беременности с осложнениями по триместрам и в родах не обнаружеHO.

Отметим, что угроза прерывания беременности во втором триместре положительно коррелировала со значениями гемостаза беременных женщин с НДСТ, как индекс $А П Т В(R=0,5584, p=0,0379)$ и тромбиновое время $(R=0,5584, p=0,0379)$ во втором триместре.

В третьем триместре беременности в структуре осложнений гестации все еще преобладали такое осложне- 
ние, как анемия, частота встречаемости которой достигает более чем 64\% у женщин с НДСТ.

Уровень гемоглобина в третьем триместре является отрицательным с очень высокой степенью достоверности коррелируется с временем излития околоплодных вод относительно начала родовой деятельности ( $\mathrm{R}=0,5825, \mathrm{p}=0,00008)$ - то есть в группе женщин с низкими показателями гемоглобина излитие околоплодных вод происходило раньше начала родовой деятельности.

Кроме того, в третьем триместре у женщин с НДСТ присутствовали прогностические маркеры, которые свидетельствовали о развитии угрозы преждевременных родов, отмечалось наличие миопии $(R=0,46, p=0,002)$, повышенные уровни индекса АПТВ ( $R=0,547, p=0,0005)$ и $\mathrm{PФMК}(R=0,48, p=0,002)$.

Самую сильную связь с фактом развития и прогрессирования гестоза имел феномен прогрессирующего снижения уровня тромбоцитов во время беременности $(\mathrm{R}=$ $-0,488, p=0,00139$ ).

Достоверная (уровень $\mathrm{p}<0,03)$ сильная $(\mathrm{R}=+0,866)$ взаимосвязь была определена между развитием гестоза в третьем триместре и сдвигом в первом триместре беременности в сторону гиперкоагуляции таких показателей, как - индекс АПТВ, проторомбин по Квику, МНО, тромбиновое время, фибриноген и уровень РФМК. С сданными параметрами были связаны гипоксии плода и факт обнаружения синдрома задержки развития плода в третьем триместре беременности, сила и достоверность связи была идентичной таковым для гестоза, что доказывает общность патогенеза этих осложнений у беременных с НДСТ.

\section{Алгоритм веАения \\ беременности и роАов у женшин \\ с неАифференчированной \\ Аисп^азией соеАините^ьной ткани}

По результатам данных, полученных на первом этапе исследования, был выработан алгоритм ведения пациенток с недифференцированной дисплазией соединительной ткани.

При первой явке женщины в женскую консультацию должен быть верифицирован диагноз недифференцированная дисплазия соединительной ткани.

Если наличие НДСТ подтвердилось, то необходимо в сроки, приближенные к остальному объёму обследований, провести расширенную гемостазограмму, включающую определение количества тромбоцитов, времени свертывания крови, время кровотечения, агрегации тромбоцитов, активированного частичного тромбопластинового времени (далее - АЧТВ), фибриногена, определение протромбинового (тромбопластинового) времени, МНО, содержания растворимых фибрин - мономерных комплексов, проторомбина по Квику, фибриногена В, антитромбина III, Д - димеров, уровня протеина C.

Кроме того, необходимо, чтобы пациентку проконсультировал хирург и терапевт на предмет наличия экстрагенитальной патологии, характерной для НДСТ.

После выполнений первого блока анализов необходимо начать профилактические мероприятия в виде назначения диеты с повышенным содержанием олигопептидов и гликозаминогликанов, принятием магния В6, то есть осуществление магниевой терапии. Магний В6 назначается по 2 таблетки 2 раза в день с момента установления беременности и до 36 недель. При обнаружении хронической венозной недостаточности можно назначить диосмин 600 мг в день, длительность курса - 4 недели, повторно раз в триместр.

Значимые изменения зарегистрированы при анализе показателей оксипролина и магния в процессе магниевой терапии. Если до начала лечения уровень оксипролина у женщин с НДСТ значительно превышал таковой у женщин контрольной группы, то на фоне лечения происходила выраженная нормализация уровня оксипролина к 22 неделям (на 50\%), а к 34 неделям зарегистрировано его абсолютное соответствие уровню контрольной группы. Тогда как в подгруппе 1 основной группы наблюдалось статистически значимое повышение уровня оксипролина, свидетельствующее о прогрессирующей деградации коллагенов с увеличением срока беременности за счет тканей материнского и/или плодового происхождения.

Прием магния приводит к полной нормализации показателя к 22 неделям и незначительному его превалированию $(11,4 \%)$ в 34 недели беременности $(P>0,05)$. Уровень магния в крови беременных с НДСТ не получавших препараты магния оставался стабильно на протяжении всей беременности.

В зависимости от показателей гемостазиограммы необходимо выделять группы риска по таким осложнениям, как плацентарная недостаточность, хроническая внутриутробная гипоксия и задержка внутриутробного развития плода - в случае выявления низких (менее 50\%) функциональных показателях агрегационной активности тромбоцитов, а так же гестоз - в случае высоких значений РФМК в 1 и 2 триместре беременности, роста уровня Д-димеров в эти же сроки и явлений дезадаптации в системе гемостаза с ранних сроков беременности. 
Повторять расширенное исследование целесообразно не чаще 1 раза в триместр. Последнее исследование необходимо проводить в сроке 36 недель для определения состояния системы гемостаза, риска кровотечений (в случае выраженной дезадаптации коагуляционного гемостаза или угнетения сосудисто-ромбоцитарного гемостаза).

Применение подобного алгоритма ведения в группе из 800 пациенток улучшить акушерские и перинатальные исходы после проведения данного курса лечения.

В первом триместре беременности в группах женщин с НДСТ достоверных различий по частоте встречаемости осложнений и их структуре не было.

Во втором триместре беременности во 2 группе женщин с НДСТ удалось добиться снижения частоты встречаемости таких осложнений, как угроза прерывания беременности и анемия. В третьем триместре у женщин второй группы снизилась частота угрозы прерывания, анемии, гестоза и гипоксии плода $(p<0,05)$. Но не было зафиксировано снижения частоты встречаемости таких осложнений, как низкая плацентация и синдром задержки внутриутробного развития плода.

В первой группе беременных женщин с НДСТ процент экстренных оперативных родоразрешений составил 19,2\%, во второй группе аналогичный показатель был равен только 11,9\%. В структуре показаний к экстренному разрешению у женщин с НДСТ на первом месте находились признаки нарастающей гипоксии плода, на втором - аномалии родовой деятельности. На третьем (только в 1 группе) - преждевременная отслойка нормально расположенной плаценты. Во второй группе этот диагноз не фиксировался.

Срок родов в 1 группе составил 38недель, во второй - - 38, в третьей - 39,5 недель. Излитие околоплодных вод до срока 37 недель встречалась у 3(4.1\%) женщин из 1 группы и у 1 (2,4\%) женщины из второй группы. В контрольной группе все эпизоды преждевременного излития околоплодных вод происходили в сроке более 38 недель.

Вес новорожденных женщин с НДСТ был достоверно меньше, чем аналогичный показатель у здоровых женщин, $\mathrm{p}<0,004$ при сравнении всех групп.

Аналогичная динамика наблюдалась и для роста новорожденных, $\mathrm{p}<0,0003$ для групп сравнения. В то же время вес новорожденных во 2 группе был несколько больше, чем в первой группе

Обращают на себя внимание сниженные показатели оценки новорожденных по шкале Апгар в группах жен- щин с НДСТ, так, для 1 группы средние значения этого показателя составили 8 балла, для второй группы - так же 8 балла, а для 3 группы - 8 балла. Различия в тесте сравнения Манна-Уитни между показателя новорожденных женщин с НДСТ и женщин без НДСТ были достоверными $(p<0,005)$. Только 51\% новорожденных в 1 группе имел оценку на первой минуте 8 баллов. Оценки по школе Апгар 9 баллов и более на первой минуте не было ни у одного новорожденного. В то же время обращает на себя внимание тот факт, что во второй группе суммарный процент детей, родивших с оценкой по шкале Апгар 5 и 6 баллов был меньше, чем аналогичный показатель в 1 группе (10\% и $23 \%$ соответственно).

Хроническая фетоплацентарная недостаточность в доношенном сроке встречалась у 31,5\% женщин 1 группы и у 28,6\% женщин 2 группы, на этом фоне задержка внутриутробного развития развилась у 5,5\% и 4,7\% женщин соответственно. Женщины контрольной группы не имели хроническую фетоплацентарную недостаточность.

Травмы родовых путей встречались у 26,1\% женщин контрольной группы, в группе женщин с НДСТ на ретроспективном этапе этот показатель составил 35,6\%, на проспективном - 33,3\%. Структуру акушерского травматизма у пациенток на этапах исследования отражена в диаграмме на рисунке 34. У трёх женщин из 1 группы была обнаружена гематома влагалища, потребовавшая вскрытия и прошивания. Во второй группе такого осложнения зафиксировано не было.

У 11\% женщин 1 группы были зафиксированы осложнения в виде акушерских кровотечений, аналогичный показатель у женщин 2 группы было меньше и составил 9,5\%.

Таким образом, из представленных данных видно, что предложенный алгоритм ведения беременных с НДСТ оказывает благоприятное влияние на акушерские и перинатальные исходы.

\section{Схема вемение беременности женшин

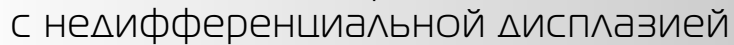 соеАинитеАьной ткани}

Любое ведение беременности акушером-гинекологом, как и обследования больных другим врачом, подчинено определенному алгоритму необходимых действий, который может быть представлен в виде схемы с последующим описанием каждого пункта данной схемы.

Схематически ведение беременности женщин с недифференциальной дисплазией соединительной ткани условно можно разделить на два основных направления:

1. Ведение условно здоровой женщины; 
2. Ведение женщины, которая знала до беременности, что она больна дисплазией соединительной ткани.

Каждый из данных направлений включает в себя необходимый алгоритм действий. Рассмотрим каждое из данных направлений.

\section{Вемение беременности условно зАоровой женшины}

При отсутствии видимых проявлений недифференциальной дисплазии соединительной ткани или фиксации в медицинской карте наличия НДСТ, беременная может считаться условно здоровой женщиной. В данном случае необходимо назначить консультацию и осмотр терапевта для того, чтобы определить наличие или отсутствие фенотипических маркеров НДСТ.

Согласно исследования, проведенному Лукиной Т.С., чаще всего у женщин с недифференциальной дисплазией соединительной ткани встречается проявление дизэмбриогенеза [7], то есть небольшие внешние фенотипические проявления недифференциальной дисплазии соединительной ткани. Они есть у каждого человека, но при отсутствии дисплазии соединительной ткани число данных аномалий или стигм не должно превышать 5, к числу стандартных аномалий можно отнести широкую переносицу, неправильную форму ушной раковины и т.д.

Кроме того, терапевт вправе проводить антропометрические исследования, которые основываются на следующих измерениях:

- длина верхней конечности - расстояние между выступающей точкой на крае акромиального отростка лопатки и дистальной точкой ногтевой фаланги 3-го пальца;

- длина плеча - расстояние от выступающей точки на крае акромиального отростка лопатки до верхней точки головки лучевой кости;

- длина предплечья - расстояние от нижней точки шиловидного отростка лучевой кости до верхней точки головки лучевой кости;

- длина кисти - расстояние между проекцией шиловидной кости на продолжение линии третьей пястной кости до самой дистальной точки ногтевой фаланги 3-го пальца;

- длина нижней конечности - расстояние от большого вертела до пола;

- длина бедра - расстояние между верхним краем лонного сочленения и серединой медиального мыщелка большеберцовой кости;

- длина голени - расстояние между серединой медиального мыщелка большеберцовой кости и нижней точкой на внутренней лодыжке;
- длина стопы - расстояние от пяточного бугра до конца ногтевой фаланги 2-го пальца.

Ведение женшины, которая знала $\triangle$ беременности, Что она больна Аисплазией соеАинительной тКани

Многие женщины, находясь еще в юношеском возрасте, узнают о наличии недифференциальной дисплазии соединительной ткани, что фиксируется в их медицинских картах. При наличии у беременных женщин диагноза НДСТ до беременности в первую очередь необходимо проведение специализированного приема, который проводится до 12 недель. В ходе данного приема производятся исследования отсутствия висцеральных проявлений НДСТ, оксипролина и магния в сыворотки крови.

После проведения специализированного приема необходимо провести расчет оценки риска, который основывается на данных программы «Step DST», работа и преимущества которой были описаны выше.

В том случае, если женщина, относящаяся к группе высокого риска по НДСТ, не отказывается от проведения терапии препаратами магния, то осуществляется контроль магния и оксипролина в 22 и 34 недели, что помогает корректировать дозировку магния и при необходимости ее менять. А госпитализация пациентки группы высокого риска планируется на 38 недели беременности, если нет основания для госпитализации на сроке раньше, чем 38 недель беременности.

Однако необходимо отметить, что не все пациентки с НДСТ группы высокого риска обладают достаточным финансированием для проведения терапии магниевыми аппаратами, поэтому женщинам данной группы с недостаточным финансированием необходимо произвести дополнительное финансирование, которое осуществляется государством, что предполагает наличие бесплатных услуг и препаратов для беременных.

Отметим, что для того, чтобы использовать дополнительное финансирования, необходимо наличие полиса OMC, который действует лишь в государственных органах здравоохранения.

К списку препаратов, которые могут предоставляться бесплатно относят фолиевую кислоту, витамин Е, кальция карбонат и т.д. Однако данный перечень каждый год может изменяться Министерством Здравоохранения.

В связи с этим у беременных с НДСТ помимо указанной схемы можно использовать алгоритм клинико-гемостазиологических исследований. Один из последних 
таких алгоритмов был предложен П.А. Кирющенковым с соавторами. Он обобщает существующие анамнестические данные, анализ клинической ситуации с выполнением общих оценочных, а при необходимости - отдельных специальных гемостазиологических тестов, установление диагноза и подбор необходимой терапии [8].

При наличии любой патологии беременной женщины с НДСТ в первом триместре рекомендуется специальная диета, которая характеризуется повышенным содержанием белков и гликозаминогликанов, то есть тех средств, которые позволяют регулировать тонус и моторику желудочно-кишечного тракта, витамин Е в дозе 400 ME/сутки. При назначении тех или иных препаратов необходимо учитывать, что препараты, понижающие коагуляционный потенциал, могут привести к снижению геморрагических проявлений у женщин синдромом мезенхимальной дисплазии. Кроме того, необходимо помнить, что дисплазия соединительной ткани в большинстве случаев характеризуется облигатным магниево-дефицитным состоянием[9] [10].
Лечение беременных с диагнозом НДСТ проводится посредствам назначения таблетированных препаратов магния, что фиксируется в общей схеме ведения беременных женщин с НДСТ и считается оправданным с позиции рациональной фармакотерапии беременных. Кроме того, данное лечение может проводится без лабораторного подтверждения магниевого дефицита в связи с малой его информативностью. Еще одной причиной проведения своевременного лечения таблетированными препаратами магния является то, что магний необходим для нормализации состояния системы гемостаза [11].

С целью коррекции геморрагического синдрома у пациентов с НДСТ применяются средства местного и общего действия. Для остановки кровотечения местно чаще всего используются хирургические методы, гемостатическая губка, системно - препараты антифибринолитического действия, прежде всего - транексамовая кислота. По общепринятым показаниям - инфузионно-транфузионная терапия. При массивных кровопотерях оправдано применение рекомбинантных факторов свёртывания крови.

\section{ЛИТЕРАТУРЫ}

1. Васильев В.Е. / Пути совершенствования медико-социальной помощи женщинам и детям при угрозе невынашивания: Автореф. дис. канд. мед. наук. СПб; 1994. 17 c.

2. Фадеева Т.С./ Беременность у женщин с дисплазией соединительной ткани. Вестник Российского Государственного медицинского университета 2007; (7): 171-172.

3. Концепция охраны репродуктивного здоровья населения России на 2000-2004 годы// АВ 2001 г. Выпуск 8 Охрана репродуктивного здоровья населения на 2000-2004 гг. [Электронный ресурc] -URL: http://iam.duma.gov.ru/node/8/4534/15428

4. Конституция Российской Федерации 2015 года// [Электронный ресурс] -URL: http://base.garant.ru/10103000/2/\#block_2000

5. Концепция охраны репродуктивного здоровья населения России на 2000-2004 годы// АВ 2001 г. Выпуск 8 Охрана репродуктивного здоровья населения на 2000-2004 гг. [Электронный ресурc] -URL: http://iam.duma.gov.ru/node/8/4534/15428

6. Масленников А.В. / Особенности течения беременности и родов у женщин с недифференцированной дисплазией соединительной ткани// Дисс. ... канд. мед. наук Уфа 2014-116с.

7. Лукина Т.С. / Оптимизация математического моделирования и прогнозирования анализа течения беременности и родов у женщин с недифференциальной дисплазией соединительной// Автореф.дисс.канд.мед.наук.-М.,2003.— 57 с.

8. Causal relationship between hyperfibrinogenemia, thrombosis, and resistance to thrombolysis in mice / K.R. Machlus, J.C. Cardenas, F.C. Church, A.S. Wolberg // Blood.— 2011.—Vol. 117.—P. 4953-4963.

9. Шабалов Н.П. Наследственные болезни соединительной ткани / Н.П. Шабалов, В.Г. Арсентьев // Педиатрия. Национальное руководство: в 2 т. 一 М.: ГЭ0ТАР - Медиа, 2009.- - Т. 1.-С. 298-320.

10. Сидорович О.В., Горемыкин В.И., Елизарова С.Ю., Нестеренко 0.В. / Способ объективизации диагностики недифференцированной дисплазии соединительной ткани у детей с помощью количественного метода //Международный журнал экспериментального образования. — 2013.—№ 11-2. — С. 53-55.

11. Кудинова Е.Г. Генетические тромбофилии у девушек с мезенхимальными дисплазиями / Е.Г. Кудинова // Сибирский медицинский журнал.- 2011.Т. 26, № 3, Вып. 2.- С. 97-99.

(с Фадеева Татьяна Сергеевна (Fdv_tana@mail.ru ), Бицадце Виктория Омаровна ( Vikabits@mail.ru ).

Журнал «Современная наука: актуальные проблемы теории и практики» 